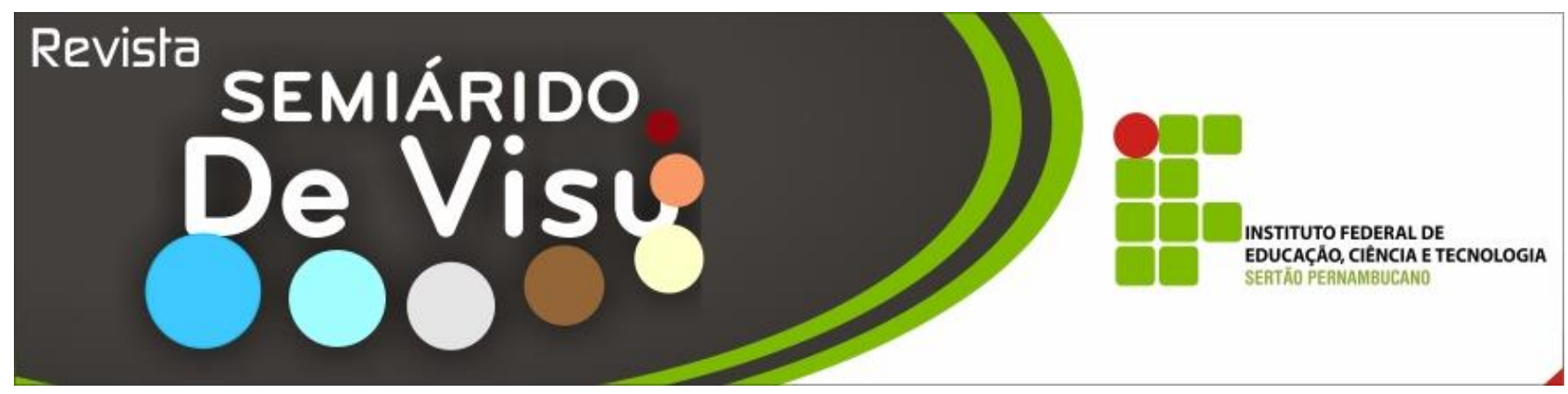

\title{
Percepção dos alunos do ensino médio sobre as aulas de educação física
}

\author{
Elisiane Pereira de Lima ${ }^{1}$, Thiago Ricardo dos Santos Tenório ${ }^{2}$ \\ ${ }^{1}$ Autarquia Educacional de Serra Talhada. Av. Afonso Magalhães - AABB - Serra Talhada - Pernambuco- Brasil. CEP: 56912-380 / \\ Telefone: (87) 3831-231. \\ ${ }^{2}$ Instituto Federal do Sertão Pernambucano - Campus Serra Talhada. R. Irineu Magalhães, 985 - AABB - Serra Talhada - \\ Pernambuco - Brasil. CEP: 56912-140/ Telefone: (87) 8106-6368. / E-mail: ${ }^{1}$ eliis.lima@ hotmail.com; ${ }^{2}$ thiago.esef@ gmail.com
}

\begin{abstract}
RESUMO:
A atividade física é entendida como meio de promoção de saúde, estando inserida como a cultura corporal de movimento nas aulas de Educação Física visa integrar o aluno na sociedade de forma que o mesmo se torne atuante diante da sua realidade. O Ensino Médio é caracterizado pela presença de um público adolescente que, passando por mudanças biopsicossociais, apresentam diversas reações diante das aulas de Educação Física. Desta forma, o presente trabalho tem como objetivo analisar por meio de revisão bibliográfica narrativa a percepção dos alunos do Ensino Médio sobre as aulas de Educação Física. Por meio da compilação e síntese de estudos anteriores, conclui-se que aulas bem elaboradas e com um bom domínio do professor diante das possíveis adversidades vivenciadas pelos alunos são consideradas essenciais no currículo escolar.
\end{abstract}

Palavras-chaves: Adolescentes, Atividade Física, Ensino.

\section{High school students' perceptions of the physical education classes}

\begin{abstract}
:
Physical activity is understood as a means of health promotion and is inserted as the body culture movement in Physical Education aims to integrate the student in the form of society it becomes active before their reality. The School is characterized by the presence of a teenage audience that, through biopsychosocial changes, have different reactions to the physical education classes. Thus, this study aims to analyze through literature narrative review the perception of high school students about the physical education classes. Through the compilation and synthesis of previous studies it was concluded that well-designed lessons with a good teacher domain on the possible adversities students say like school and consider essential in the school curriculum.
\end{abstract}

Key words: Adolescents, Physical Activity, Education. 


\section{Introdução}

$\mathrm{A}$

Educação Física é definida de acordo com os Parâmetros Curriculares Nacionais (PCNs) $n^{\circ} 15 / 98$ como a "cultura corporal de movimento" e que, por ser uma disciplina curricular, é de direito e dever de todo aluno a participação na mesma, trazendo o desafio ao professor de adequar e inovar suas aulas para que chame a atenção deste público (COLETIVO DE AUTORES, 1992).

Estando presentes em nosso contexto cultural, os jogos, o esporte, a dança, a luta e ginástica compõem o eixo temático da Educação Física do Ensino Infantil ao Ensino Médio e tem o papel de proporcionar vivências voltadas para o desenvolvimento / transformação do biopsicossocial, bem como da saúde e qualidade de vida (BRASIL, 1998).

O Coletivo de Autores nos mostra ainda que este ensino voltado para transformação encontra-se embasado na concepção da abordagem pedagógica crítico-superadora, proporcionando assim uma melhor reflexão sobre assuntos da realidade do aluno, com o intuito de que o mesmo possua uma visão crítica e possa intervir nesta mesma realidade (COLETIVO DE AUTORES, 1992).

A Educação Física no Ensino Médio tem o papel de consolidar conhecimentos anteriores, já vistos no Ensino Fundamental, e ainda conscientizá-los sobre a importância desta disciplina em um estilo de vida saudável e autônomo, visto que o público destas turmas está passando por diversas mudanças, o que pode dificultar ainda mais o papel do professor.

Estas mudanças são características da adolescência/puberdade e são identificadas nas aulas de Educação Física quando os alunos apresentam maior indisposição para a prática da mesma, devido, especialmente, às mudanças hormonais e fisiológicas.

Segundo Becker (2003), devido às alterações físicas, psíquicas e sociais, é preciso que o professor esteja em inovação constante, buscando levar para as suas aulas a realidade e a vivência dos seus alunos a fim de motivá-los.

De forma geral, percebe-se que há uma desmotivação nas aulas de Educação Física por parte deste público. Sendo assim, este trabalho tem como justificativa o interesse pelo tema e o intuito de analisar a percepção dos alunos sobre a importância desta disciplina. Dessa forma, o objetivo do presente estudo é investigar e descrever, por meio de revisão bibliográfica narrativa, a percepção dos alunos do ensino médio sobre a Educação Física, seus benefícios e as possíveis melhorias para a disciplina.

\section{Material e métodos}

Essa pesquisa trata-se de um estudo exploratório com análise qualitativa. Foi realizada uma revisão bibliográfica narrativa, com busca de literatura nas bases de dados Scielo (Scientific Electronic Library Online) e Google Acadêmico, bem como a utilização de livros como suporte básico da literatura clássica sobre a temática.

\section{Resultados e Discussão}

\section{Atividade Física e Educação Física Escolar}

A atividade física está presente na vida humana desde a pré-história, o homem primitivo utilizava-se inconscientemente de técnicas como o correr, saltar, trepar e rolar que, posteriormente, foram conhecidas como os princípios básicos da ginástica. Para Ramos (1982) essas ações foram nomeadas como uma "Educação Física espontânea e ocasional".

No Brasil, os primeiros registros da atividade física são desde o seu descobrimento, relatos nas cartas de Pero Vaz de Caminha mostravam que os índios e escravos utilizavam ainda a cultura primitiva dos movimentos. Necessitavam do nado, caça, pesca, corridas e saltos para a sobrevivência, de aprimoramento das suas armas de caça e busca/luta por territórios; da dança e recreação para o culto aos deuses e festas (GUTIERREZ, 1972).

Em 1882 a Educação Física foi inserida no currículo através de Rui Barbosa e esteve sob forte influência militar, pois o objetivo do ensino baseava-se em disciplina, obediência e subordinação dos alunos para com os 
professores e visava apenas a preparação física para defender o país e seus ideais, enaltecendo assim a aptidão física (SOUZA NETO et al., 2004).

Do período imperial (1822) ao período contemporâneo (1980), a atividade física passou por diversos momentos, porém sempre voltada para a linha militar, médica, esportivista e competitiva. Nessa ocasião era considerada como uma forma de favorecimento e educação do corpo, tendo como meta a obtenção de um físico saudável e organicamente equilibrado (BRASIL, 1998).

A partir de 1980 a Educação Física passou a ser definida como a cultura corporal de movimento, surgindo em crítica à esportivização da Educação Física Brasileira. Diversos autores conceituaram a cultura corporal de movimento, uma das primeiras publicações foi de Dieckert (1985) que buscava uma Educação Física diferente da que tinha sido vista até então, a do "esporte para todos", mais humana e que se engajasse na cultura própria do povo em que estava inserido, no caso o povo brasileiro.

Essa cultura própria do nosso povo foi definida pelo autor como:

\begin{abstract}
“elaborações que as pessoas realizam em torno de suas próprias práticas corporais, construídas e reconstruídas em seu país capoeira, jogos de diferentes regiões, danças brasileiras - elementos da "cultura corporal que vive no Brasil e no povo brasileiro". (SOUZA JR, et al, 2011. p.395).
\end{abstract}

Dessa forma, a cultura corporal de movimento é a junção dos conhecimentos e representações, tanto utilitários e de adaptação ao meio, como os lúdicos, por divertimento e prazer.

A Educação Física brasileira tem como objetos de ação e reflexão os jogos e brincadeiras, a dança, a ginástica, as lutas e os esportes (BRASIL, 1998). O coletivo de autores afirma que: "os temas da cultura corporal, tratados na escola, expressam um sentido/significado onde se interpenetram, dialeticamente, a intencionalidade/objetivos do homem e as intenções/ objetivos da sociedade" (COLETIVO DE AUTORES, 1992).
Dessa forma a Educação Física tem o corpo e o movimento como seu objeto de estudo, e os temas acima citados englobam o eixo temático a ser transmitido ao longo da vida escolar, cabendo ao professor selecioná-los de forma que, desde cedo, melhore a expressão corporal, consciência do corpo e da saúde e através disso proporcionar aos seus alunos todos os benefícios dessas aulas e de um estilo de vida mais saudável (SOLER, 2003).

Atualmente a Educação Física continua a lutar por sua identidade e reconhecimento, buscando dessa forma, conquistar um lugar de respeito junto às demais disciplinas do currículo escolar. AEducação Física está em busca de seus princípios fundamentais, questionando quais são seus objetivos, seus conteúdos, suas metodologias de modo a dizer da sua importância junto aos demais saberes escolares.

\section{A Educação Física no Ensino Médio}

A Lei de Diretrizes e Bases (LDB) de $\mathrm{n}^{\circ}$ 9.394/96, no art.36 define o Ensino Médio como a última etapa da educação básica e esquematiza as diretrizes gerais para a organização curricular no Ensino Médio, definindo como seus objetivos:

I - a consolidação e o aprofundamento dos conhecimentos adquiridos no Ensino Fundamental, possibilitando o prosseguimento de estudos;

II - a apresentação básica para o trabalho e a cidadania do educando, para continuar aprendendo de modo a ser capaz de se adaptar com flexibilidade a novas condições de ocupação e aperfeiçoamento posterior;

III - o aprimoramento do educando como pessoa humana, incluindo a formação ética e o desenvolvimento da autonomia intelectual e do pensamento crítico;

IV - a compreensão dos fundamentos científico-tecnológicos dos processos produtivos, relacionando a teoria com a prática, no ensino de cada disciplina (Brasil, 1999).

O público que compõe os três anos do ensino médio, geralmente está vivenciando a adolescência, que é a fase onde segundo Cool, Palácios \& Marquesi (1995, p.263) "se estende 
dos 12-13 até aproximadamente ao final da segunda década de vida. É uma etapa de transição entre a infância e a etapa adulta”.

Por ser um momento de transição, as mudanças físicas causam muitas vezes isolamento, vergonha do corpo, ocorrendo uma mudança no psicológico e social (BECKER, 2003). Tais mudanças provocam desmotivações com relação às aulas, podendo-se verificar que o papel do professor será ainda mais difícil, pois uma aula em que todos estejam motivados é uma tarefa para poucos, uma vez que esta depende de uma série de fatores internos e externos (OLIVEIRA, 2006).

Devido a estes fatores, o Ensino Médio se torna ainda mais importante, pois compreende uma fase de formação dos alunos, devendo ser incorporada por meio de metodologias diferenciadas de aprofundamento, compreensão e discussão sobre assuntos pertinentes e trabalhados no Ensino Fundamental.

Estando presente no âmbito escolar, a Educação Física apresenta sua devida importância neste papel, como apresentar ao adolescente o seu corpo em sua totalidade, expresso através dos movimentos, sentimentos e atuação diante dos seus próprios conflitos (MATTOS \& NEIRA, 2000).

Sobre a Educação Física no Ensino Médio, os Parâmetros Curriculares Nacionais recomendam determinadas propostas para o seu desenvolvimento, como orientações objetivas aos professores da disciplina para que possam executar suas aulas de forma lúdica e educativa, possibilitando a aprendizagem em diversos assuntos aos alunos, tornando-os cidadãos capazes de resolver as mais diversas situações da vida cotidiana (BRASIL, 1999).

Os Parâmetros Curriculares Nacionais (PCNs) (BRASIL, 1999), destacam as principais competências e habilidades a serem desenvolvidas:

- Compreender o funcionamento do organismo humano, de forma a reconhecer e modificar as atividades corporais, valorizando-as como recursos para a melhoria de suas aptidões físicas;
- Desenvolver as noções conceituais de esforço, intensidade e frequência, aplicando-as em suas práticas corporais;

- Refletir sobre as informações específicas da cultura corporal, sendo capaz de discerni-la e reinterpreta-las em bases científicas, adotando uma postura autônoma na seleção de atividades e procedimentos para a manutenção ou aquisição da saúde;

- Assumir uma postura ativa, na prática das atividades físicas, e consciente da importância delas na vida do cidadão;

- Compreender as diferentes manifestações da cultura corporal, reconhecendo e valorizando as diferenças de desempenho, linguagem e expressão;

- Participar de atividades em grandes e pequenos grupos, compreendendo as diferenças individuais e procurando colaborar para que o grupo possa atingir os objetivos a que se propôs;

- Reconhecer na convivência e nas práticas pacíficas, maneiras eficazes de crescimento coletivo, dialogando, refletindo e adotando uma postura democrática sobre os diferentes pontos de vista propostos em debates;

- Interessar-se pelo surgimento das múltiplas variações da atividade física, enquanto objeto de pesquisa, áreas de grande interesse social e mercado de trabalho promissor;

- Demonstrar autonomia na elaboração de atividades corporais, assim como capacidade para discutir e modificar regras, reunindo elementos de várias manifestações de movimento e estabelecendo uma melhor utilização dos conhecimentos adquiridos sobre a cultura corporal.

Os Parâmetros Curriculares Nacionais destacam ainda temas que se correlacionam com seus objetivos e que o professor deve inserir nas aulas a fim de contribuir tanto para as aulas de Educação Física quanto para a realidade de vida dos seus alunos, esses temas foram chamados de transversais e são eles: ética, pluralidade cultural, meio ambiente, trabalho e consumo, orientação sexual e saúde (BRASIL, 1999).

É de suma importância salientar que, ao incluir os temas transversais nas aulas de Educação Física significa dar auxílio aos alunos diante da sociedade e de seus problemas sociais, tornando-os indivíduos ativos, conscientes e 
com uma melhor qualidade de vida. Assim, ensinar Educação Física não significa tratar apenas de técnicas e táticas, mas sim oferecer uma concepção ampla voltada à formação do cidadão crítico.

Percepção dos alunos sobre as aulas de educação física

Diversos estudos já buscaram entender o que os alunos entendem/acham sobre as aulas de Educação Física e sua devida importância, podendo encontrar resultados tanto positivos quanto negativos.

Brandolin et al. (2015), descreveu em seu estudo que a grande maioria do público que participou da sua entrevista, considerou a Educação Física uma disciplina de prática prazerosa. Em se tratando da importância da mesma no currículo escolar, os alunos a classificaram como a terceira mais importante, ficando depois de português e matemática. Este fato pode ser justificado pelo fato de que o Ensino Médio, por ser a última fase da educação básica, é caracterizada pela predominância das disciplinas exigidas no Exame Nacional do Ensino Médio e em vestibulares, especialmente português e matemática.

Ainda sobre o estudo de Brandolin et al. (2015), foi observado que o nível de satisfação com as aulas foi em maior proporção do público masculino. Esta pesquisa foi realizada na rede pública de educação e os alunos enfatizaram que o espaço inadequado, presente em muitas aulas, não interfere no seu desenvolvimento nem diminui a satisfação com a mesma.

Ferreira et al. (2014), apresenta em sua pesquisa dados semelhantes, onde a quantidade de alunos que está satisfeita com as aulas e que sente prazer em participar da mesma é predominantemente masculina.

Cardoso \& Nunes (2014) tiveram resultados também positivos quanto ao prazer durante a aula e importância da disciplina no currículo escolar, pois, para eles a prática da Educação Física proporciona saúde e um momento de interação entre a turma. Estes resultados corroboram com os de Castuera (2004), o qual mostrou que a Educação Física deve contemplar como essencial em suas aulas, a promoção de saúde e a conscientização de um estilo de vida saudável.

Quando questionados sobre o porquê de gostarem ou não gostarem das aulas, no estudo de Costa et al. (2016), os alunos que gostam das aulas justificam sua resposta pelo fato de que esta disciplina trabalha o esporte, proporciona melhora da saúde e que quando há uma boa elaboração e motivação por parte do professor, a satisfação em participar se torna ainda maior.

Dentro de configurações de instrução, os indivíduos formam avaliações de eficácia relacionais que complementam suas crenças de auto eficácia. $\mathrm{Na}$ educação física do ensino médio, por exemplo, os alunos desenvolvem um nível de confiança na capacidade do seu professor, bem como a estimativa de quão confiantes eles acham que seu professor está em sua habilidade. Jackson (2013), em uma revisão de literatura, buscou analisar as vias motivacionais dos alunos referentes à atividade física escolar, pôde concluir que a motivação é estabelecida na confiança no professor e na sua capacidade individual, e ainda, a prática de exercício como uma fonte de lazer.

Demais pesquisas já desenvolvidas sobre a auto eficácia do professor apontam que ao alcançar um bom grau em eficácia os mesmos podem ter uma mudança bastante positiva na forma de adequar-se às adversidades da profissão e acabam por transmitirem isso nas suas aulas, diante dos seus alunos (BZUNECK, 2002).

Estas mudanças apresentam-se como positivas também pelo fato de que a auto eficácia os tornam mais motivados para a elaboração de aulas com metodologias que variam, diversificam e incentivam a participação de todos, gerando, dessa forma, a motivação também aos seus alunos, conduzindo mudanças no desempenho dos mesmos (AZZI, POLYDORO \& BZUNECK, 2006; BZUNECK, 2000; ROSS, 1995).

Há uma grande quantidade de assuntos que se correlacionam e interferem nos resultados de os alunos gostarem ou não gostarem da atividade física e não participarem das aulas, como idade, gênero, metodologia dos professores e outros fatores que precisam de 
uma maior atenção, sendo que o objetivo da Educação Física é fazer com que não se privem dos seus benefícios por questões que podem ser sanadas (KUNZ, 2006).

\section{Conclusão}

Este trabalho permitiu verificar a partir de análises literárias a percepção dos alunos do Ensino Médio sobre as aulas de Educação Física, no qual foram buscados estudos que mostraram os âmbitos tanto positivos quanto negativos sobre esta disciplina na visão dos alunos.

Obedecendo aos procedimentos metodológicos desta pesquisa, podemos concluir que os diversos fatores já citados, como motivação, gênero, modalidades e metodologias inseridas na aula de Educação Física poderão causar a inserção ou evasão do aluno nesta.

Foi possível perceber ainda que o papel do professor através de um bom nível de auto eficácia proporciona o desenvolvimento de aulas mais dinâmicas, prazerosas e acessíveis, tornando-a um momento motivacional para os alunos que acabam por adquirir um nível de confiança através do seu professor.

Porém é preciso que sejam realizados mais estudos acerca destas questões, principalmente nesta fase em que a adolescência será um momento de transição para a vida adulta, e os hábitos adquiridos se tornarão positivos, se bem trabalhados nas aulas de Educação Física. Dessa forma, mais do que uma disciplina, a Educação Física deve exercer o papel de influenciadora de uma vida com hábitos mais saudáveis e fisicamente ativos.

Adicionalmente, os dados obtidos com este estudo possibilitam um entendimento, reflexão e sugestões para novas pesquisas sobre a percepção e os demais questionamentos relacionados ao tema, que por meios destes possam levar bons resultados para a vida prática e pessoal dos indivíduos, nos termos positivos aqui citados.

\section{Referências}

AZZI, R. G.; POLYDORO, S. A. J.; BZUNECK, J. A. Considerações sobre a Autoeficácia Docente. In: AZZI, R.G. e POLYDORO, S.A.J. Autoeficácia em diferentes contextos. Campinas, SP: Editora Alínea, 2006. p.149-159.

BECKER, D. O que é adolescência. 13. ed. São Paulo: Brasiliense, 2003.

BRASIL. Ministério da Educação, Secretaria da Educação Média e Tecnológica. Parâmetros Curriculares Nacionais: Ensino Médio / Ministério da Educação. Secretaria de Educação Média e Tecnológica / Brasília: Ministério da Educação, 1999.

BRASIL. Ministério da Educação. Secretaria de Ensino Fundamental. Parâmetros Curriculares Nacionais: $5^{\mathrm{a}}$ a $8^{\mathrm{a}}$ séries. Brasília. MEC/SEF, 1998.

BRANDOLIN, F. et al. A percepção dos alunos sobre a educação física no ensino médio Rev. Educ. Fís/UEM, v. 26, n. 4, p. 601610, 4. trim. 2015.

BZUNECK, J. A. A motivação do aluno: Contribuições à psicologia contemporânea. Petrópolis: Vozes, 2002.

CARDOSO, A.G., NUNEZ, P.R.M. Percepção dos alunos do ensino médio em relação às aulas de educação física. Coleção Pesquisa em Educação Física, Várzea Paulista, v. 13, n. 4, p. 125-132, 2014.

CASTUERA, R. (2004). Motivación, Trato de Igualdade, Comportamento de Discplina y Estilos de Vida Saludables en Estudiantes de Educación Física em Secundária. Tesis Doctoral. Universidad de Extremadura. Facultad de Ciencias del Deporte.

COLETIVO DE AUTORES. Metodologia do Ensino de Educação Física. São Paulo: Cortez, 1992.

COSTA, C. et al. Percepção dos alunos do ensino médio de Catanduvas quanto às aulas de Educação Física. EFDesportes. Revista 
Digital. Buenos Aires, ano 19, $\mathrm{n}^{\circ} 195$, agosto de 2014.

DIECKERT, J. et al. A Educação Física no Brasil - A Educação Física Brasileira. In: DIECKERT, J. et al. Elementos e Princípios da Educação Física. Uma Antologia. Rio de Janeiro: Ao Livro Técnico, 1985.

FERREIRA, M. L. S. et al. Pensar a Prática, Goiânia, v. 17, n. 3, p. 734-750, jul./set. 2014.

GUTIERREZ, W. História da Educação Física. S/e. Porto Alegre, Ed. Ipa, 1972.

JACKSON, B. et al. Students tripartite efficacy beliefs in high school physical education: within- and cross-domain relations with motivational processes and leisure-time physical activity. Journal of sport \& exercise psychology, v. 35, p. 72-80, 2013.

KUNZ, E. Transformação DidáticoPedagógico do Esporte. $7^{\circ}$ ed. Ijuí: Unijuí, 2006.

MATTOS, M. G.; NEIRA, M. G. Educação Física na Adolescência: construindo o conhecimento na escola. São Paulo: Phorte, 2000 .

OLIVEIRA, J. Profissão líder: desafios e perspectivas. São Paulo: Saraiva 2006.

RAMOS, J. J. Os exercícios físicos na história e na arte. São Paulo: Ibrasa. 1982.

SOUZA JR, M. et al. Coletivo de autores: A cultura corporal em questão. Rev. Bras. Ciênc. Esporte, Florianópolis, v. 33, n. 2, p. 391411, abr./jun. 2011.

SOLER, Reinaldo. Educação Física Escolar. Rio de Janeiro, RJ. Sprint: 2003.

SOUZA JR, Samuel. et al. A formação do profissional de educação física no Brasil: uma história sob a perspectiva da legislação federal no século XX. Rev. Bras. Cienc. Esporte, Campinas, v. 25, n. 2, p. 113-128, jan. 2004. 